\title{
Emerging Gene and Small Molecule Therapies for the Neurodevelopmental Disorder Angelman Syndrome
}

\author{
Nycole A. Copping ${ }^{1,3} \cdot$ Stephanie M. McTighe ${ }^{2} \cdot$ Kyle D. Fink $^{3} \cdot$ Jill L. Silverman ${ }^{1}$ (I)
}

Accepted: 26 June 2021 / Published online: 15 September 2021

(c) The Author(s) 2021

\begin{abstract}
Angelman syndrome (AS) is a rare ( 1:15,000) neurodevelopmental disorder characterized by severe developmental delay and intellectual disability, impaired communication skills, and a high prevalence of seizures, sleep disturbances, ataxia, motor deficits, and microcephaly. AS is caused by loss-of-function of the maternally inherited UBE3A gene. UBE3A is located on chromosome 15q11-13 and is biallelically expressed throughout the body but only maternally expressed in the brain due to an RNA antisense transcript that silences the paternal copy. There is currently no cure for AS, but advancements in small molecule drugs and gene therapies offer a promising approach for the treatment of the disorder. Here, we review $\mathrm{AS}$ and how loss-of-function of the maternal $U B E 3 A$ contributes to the disorder. We also discuss the strengths and limitations of current animal models of AS. Furthermore, we examine potential small molecule drug and gene therapies for the treatment of AS and associated challenges faced by the therapeutic design. Finally, gene therapy offers the opportunity for precision medicine in AS and advancements in the treatment of this disorder can serve as a foundation for other single-gene neurodevelopmental disorders.
\end{abstract}

Keywords Angelman syndrome · Seizures · Gene therapy · Animal models · Antisense oligonucleotides · Stem cells · Precision medicine $\cdot$ Delivery $\cdot$ Preclinical $\cdot$ Small molecules $\cdot$ Pharmacology $\cdot$ Treatment

\section{Introduction}

Angelman syndrome (AS) is a rare $(\sim 1: 15,000)$ neurodevelopmental disorder characterized by severe developmental delay and intellectual disability, impaired communication skills, and a high prevalence of seizures, sleep disturbances, ataxia, and motor deficits $[1,2]$. AS is generally diagnosed in patients over the age of one, as its behavioral characteristics become more readily pronounced and distinct compared to other developmental disorders [3]. Seizures are highly prevalent in AS and occur in over $80 \%$ of the population

Jill L. Silverman

jsilverman@ucdavis.edu

1 School of Medicine, Department of Psychiatry and Behavioral Sciences, MIND Institute, University of California, Research II Building 96, 4625 2nd Avenue, Suite 1001B, Davis, Sacramento, CA 95817, USA

2 Arkuda Therapeutics, 200 Arsenal Yards Blvd, Suite 220, Watertown, MA, USA

3 Stem Cell Program and Gene Therapy Center, Department of Neurology, MIND Institute, University of California, Davis, Sacramento, CA, USA
[4]. Seizures typically start early in life and are often $(\sim 1 / 3)$ resistant to classic antiepileptic drugs. They continue throughout an individual's lifetime and present across multiple seizure types including, but not limited to, absence, myoclonic, and generalized clonic-tonic seizures [5, 6]. Given their frequency and treatment resistance, seizures in AS contribute to significantly higher burden of care [7]. Currently, there is no cure for AS and the only treatments available are those designed to temporarily mitigate symptoms throughout a patient's lifetime.

AS is caused by loss-of-function of the maternally inherited UBE3A gene [8-11]. UBE3A is located on chromosome $15 \mathrm{q} 11-13$ and is biallelically expressed throughout the body but only maternally expressed in the brain due to imprinting [12-14]. The paternal copy is silenced by a long (>600 kb) non-coding RNA antisense transcript referred to as the UBE3A-ATS [15-17]. Several genetic etiologies lead to AS including de novo interstitial deletions of the maternal allele ( $\sim 65-70 \%$ of the AS population), loss-of-function mutations in the maternal allele (5-11\%), uniparental disomy resulting in two normal functioning paternal alleles (3-7\%), and various imprinting defects (3\%) [18-20]. 
Single-gene disorders are good candidates for precision gene and cellular therapies, and AS is particularly encouraging given the unique properties of $U B E 3 A$. The presence of a silent, yet functional copy of $U B E 3 A$, on the paternal allele, allows for the development of therapies directed at reactivation of the paternal copy of $U B E 3 A$ $[21,22]$. Moreover, due to the neuronal-specific monoallelic expression of $U B E 3 A$, therapies aimed at introducing a functional copy of the gene are only required the central nervous system $[12,14]$. UBE3A is highly conserved across species, making it possible to not only model the disorder but to test various preclinical therapies for safety, efficacy, and toxicity [23-27]. With recent advancements made in the field of gene and cellular therapies, as well as their delivery mechanisms, a potential cure for AS is promising [28-31]. In equally rigorous pursuit are strategies aimed to either correct the cellular pathways and downstream targets disrupted by the loss of $U B E 3 A$, which are theorized to be more likely symptomatic treatments, in comparison to comprehensive disease modifying therapies. Here, we review $U B E 3 A$ and its contribution to AS, evaluate the strengths and weaknesses of current translational rodent models and how they will help in the transition from preclinical to clinical trials, the applicability and feasibility of emerging gene and cellular therapies for AS, as well as small molecule pharmacological approaches, and challenges that face the field of precision medicine as therapies are developed.

\section{UBE3A Function}

$U B E 3 A$ encodes for a $100 \mathrm{kDa}$ ubiquitin-protein ligase E3A and was initially described as an association factor between p53 and the E6 oncoprotein of various human papillomavirus types where the E3 ubiquitin ligase binds to p53 and breaks it down using the ubiquitin proteolysis system [32]. The gene spans approximately $120 \mathrm{~kb}$ and encodes multiple isoforms that may allow for varying substrate specificity, multiple functions and unique cellular localization patterns [33,34]. UBE3A is a member of the HECT (homologous to E6-AP COOH-terminus) family of enzymes and acts to transfer activated ubiquitin to a protein, signaling it for degradation by the proteolysis system [35]. Interestingly, many of the missense and single amino acid insertion or deletion mutations seen in AS affect the C-terminal catalytic domainf [36, 37]. UBE3A also plays a role as a non-specific transcriptional coactivator of nuclear hormone receptors, independent of its ligase activity, as mutations affecting E6-AP activity do not change coactivation ability [38, 39].
While the function of UBE3A as a ubiquitin ligase protein and transcriptional coactivator is evident, the exact pathogenesis resulting from loss-of-function of the maternal allele in AS remains elusive. Interestingly, many of the missense and single amino acid insertion or deletion mutations seen in AS individuals affect the C-terminal catalytic domain, thus inferring primary ligase function, as central to mechanism $[36,37]$. There is a strong correlation between loss of the E6-AP ligase activity and AS [40] as well as numerous protein targets involved in cell proliferation and survival, synaptic function, cell signaling, and nervous system development that have been identified as UBE3A substrates [41-43]. UBE3A even acts as its own substrate [44]. Moreover, $U B E 3 A$ expression is correlated with the regulation of various genes involved in protein catabolism, cell cycle, brain morphology, and transcriptional regulation [45, 46]. Contributing to its complexity UBE3A is localized in pre- and post-synaptic neurons and localized to either cytoplasm or nucleus by isoform permitting for the widespread functional nature of the protein [47].

\section{Imprinting of 15q11-13}

Imprinting is an important epigenetic regulatory mechanism that results in the differential expression of maternal and paternal alleles in a parent-of-origin-dependent manner and is a critical factor in AS. This process occurs in the germline where methyl groups are attached to DNA in segments that are rich in cytosine-guanine dinucleotides, creating an imprinting region that regulates expression [48]. The q11-13 region of chromosome 15 spans a cluster of imprinted genes, including $U B E 3 A$, that are either maternally or paternally expressed, and have been linked to multiple neurodevelopmental disorders [49]. Within q11-13, there are two critical imprinting regions known as the Prader-Willi syndrome imprinting center (PWS-IC) and the Angelman syndrome imprinting center (AS-IC). The PWS-IC is methylated on the maternal allele and represses expression of genes upstream of $U B E 3 A$ including $M K R N 3$ (makorin/ring finger protein 3), NDN (Necdin), MAGEL2 (melanoma antigen gene family member like 2), and SNRPN (small ribonucleoprotein polypeptide N), while the PWS-IC is unmethylated on the paternal allele allowing for expression of those same genes. The AS-IC is located upstream of the PWS-IC and has been thought to help mediate the switch from paternal to maternal imprinting during oogenesis and act as a bipartite regulatory element with the PWS-IC [50]. Genes downstream of UBE3A including GABRB3, GABRA5, and HERC2 are not imprinted and biallelically expressed on both the maternal 

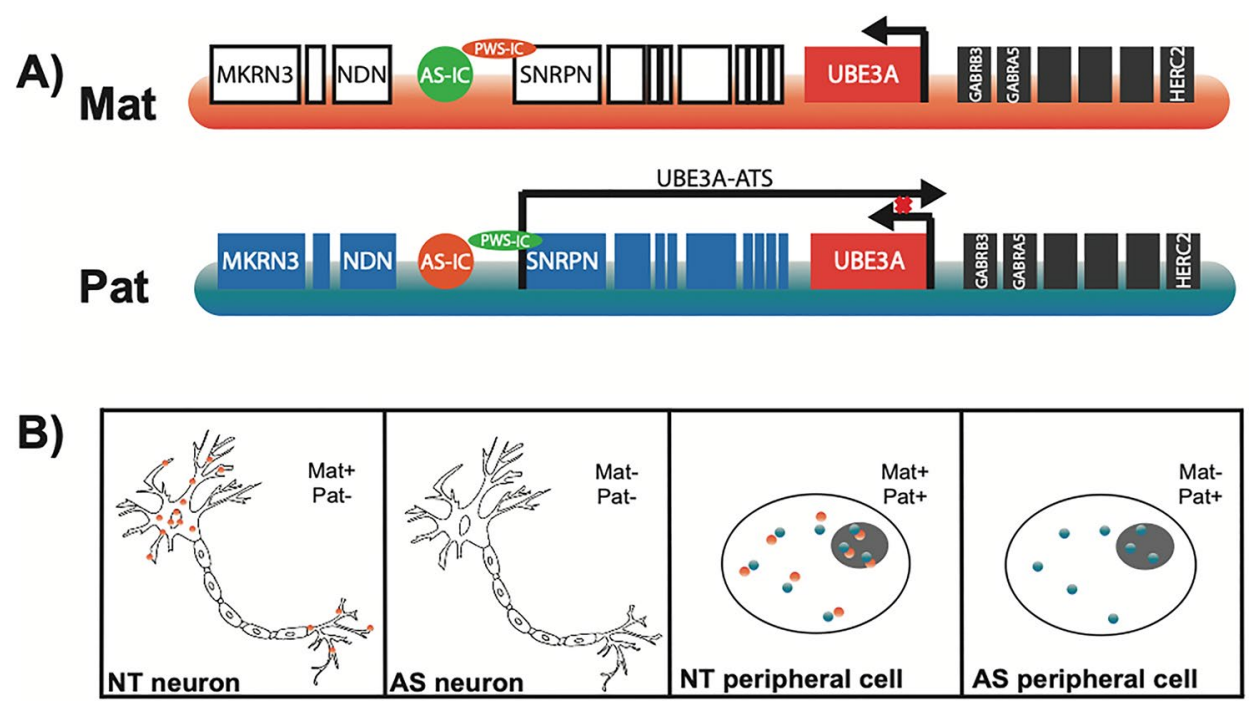

Fig. 1 Chromosome 15q11-13 and neuronal epigenetic silencing of $U B E 3 A$. A Schematic of the genomic region of 15q11-13. Blueshaded genes are paternally expressed, red-shaded genes are maternally expressed, and grey-shaded genes are biallelically expressed. White-shaded genes are silenced on the maternal copy. The PWS-IC

and paternal allele (Fig. 1A). Deletion, uniparental disomy, UBE3A missense coding errors, and imprinting etiologies of AS are characterized, in part, by the loss of methylation at SNRPN, suggesting the importance of epigenetic imprinting during development.

UBE3A is biallelically expressed throughout the body, but only maternally expressed in the central nervous system, due to silencing of the paternal allele by the UBE3A-ATS. Therefore, individuals with AS who lack a functional copy of maternal $U B E 3 A$ have no UBE3A expression in the brain while maintaining expression of UBE3A in their periphery (Fig. 1B). The UBE3A-ATS is a non-coding, polycistronic transcription unit that initiates at the PWS-IC and/or the $S N R P N$ promotor and terminates at the UBE3A promotor or $\sim 40 \mathrm{~kb}$ beyond the promotor [17, 51, 52]. The exact method of how paternal UBE3A is silenced through UBE3AATS is not fully understood; however, several mechanisms have been suggested including a transcriptional interference mechanism where RNA polymerases of the UBE3A-ATS and the gene conflict and disrupt transcription and a RNA interference mechanism where double-stranded RNA forms between the sense and antisense RNAs [53, 54]. Studies have shown that expression of $U B E 3 A$-ATS is sufficient to silence paternal $U B E 3 A$ and reduction of the UBE3A-ATS results in normal paternal expression [55]. Several attempts have been made to suppress the antisense transcript, including artificial transcription factors (ATFs) [56, 57], antisense oligonucleotides (ASOs) [58] and pro-methylation dietary supplements such as folic acid and betaine [59, 60], with some is methylated on the maternal allele (orange) and unmethylated on the paternal allele (green) while the AS-IC on both alleles is unmethylated. B Cartoon of maternal/paternal UBE3A expression in neurons and somatic cells of neurotypical (NT) individuals and those with Angelman syndrome (AS)

successes adding to evidence that precise molecular therapies are necessary to reactivate the paternal allele in AS. In fact, two ASO compounds are in phase I clinical trials (GeneTx NCT04259281; Roche NCT04428281).

\section{Preclinical Models of Angelman Syndrome}

In therapeutic development, the use of animal models is paramount in assessing both the safety and efficacy of a proposed therapeutic before advancement to regulatory processes and clinical trials. In vitro studies help to answer and investigate alterations at the cellular level and mechanistic questions [61-64], but in vivo work allows for the observation of therapeutic efficacy in a live, behaving animal. Behavioral domains relevant to AS include motor function, cognitive ability, sleep, developmental delay and seizures. Alleviation of seizures and their appearance behaviorally and via electroencphalographic (EEG) in the models is of particular importance, due to the high prevalence in the clinical AS population. Additionally, it is necessary to observe in model systems gross neuroanatomical abnormalities, fine grained histopathology, and electrophysiological patterns as they would be difficult or impossible to investigate in human patients. Finally, studies aimed to determine toxicity, safety, and dosage of therapeutics must also be conducted in vivo to observe how the therapy affects the whole organism. There are several animal models currently being used in AS research with various strengths and weaknesses that reflect their ability to model the disorder and the possibility of serving as tools to advance a therapy from bench to bedside (Fig. 2). 
Fig. 2 Gene therapy strategies for treating Angelman syndrome. The two most promising strategies to treat AS via gene therapy are to either introduce a functioning copy of UBE3A or reactivate the paternal allele by knockdown of the antisense transcript

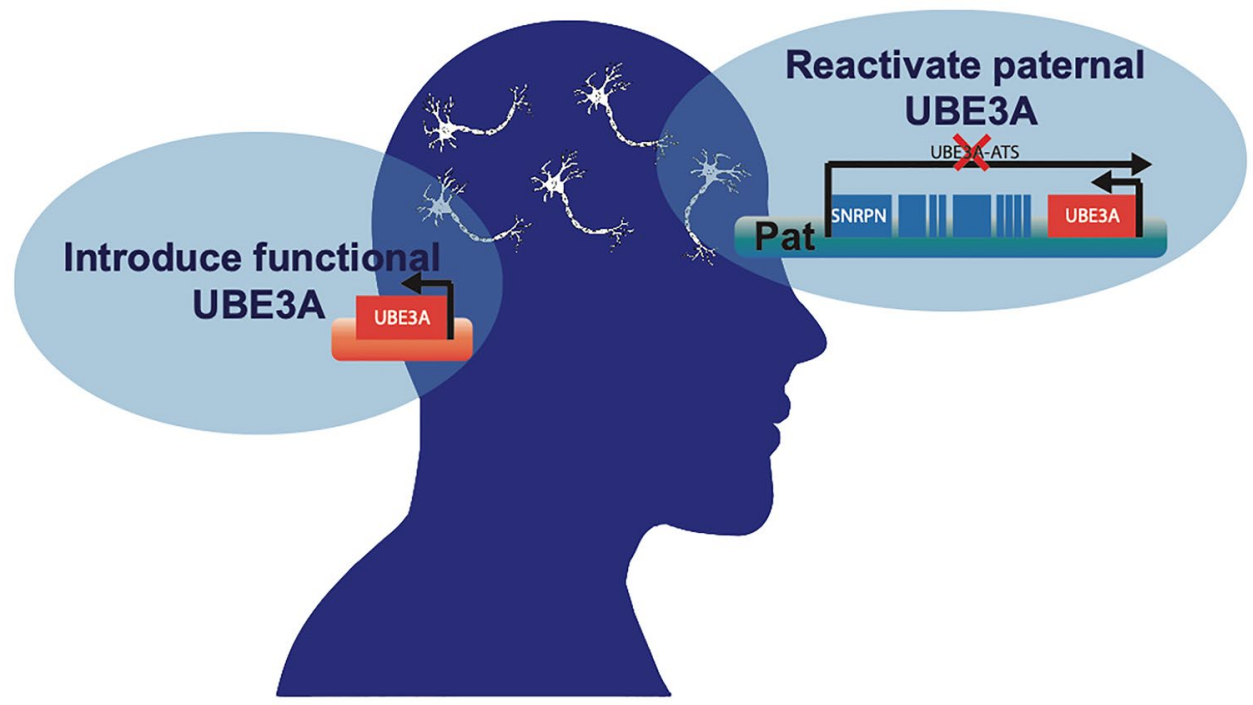

\section{Mouse Models of AS}

Several Mus musculus lines have been generated to model AS by targeting mouse chromosome 7, the homolog to human chromosome 15 's location of $U B E 3 A$, using technically innovative designs including duplications of the paternal chromosome, ligase focused mutations, and large chromosomal deletions $[65,66]$. As the majority of AS patients have a large deletion of $15 q$, an appropriate in vivo tool for investigation includes a mouse model with a large chromosomal deletion from Ube3a to Gabrb3 [67]. The most widely utilized mouse model of AS has a deletion in exon 2 resulting in a loss-of-function mutation of Ube3a [25, 68-73]. This deletion results in offspring that could inherit the deletion from either the dam (Ube $\left.3 a^{m-/ p+}\right)$ or sire $\left(U b e 3 a^{m+/ p-}\right)$. Translational phenotypes including motor impairments detected by reduced latencies to fall off a beam and accelerating rotarod, while gait analysis demonstrated variability similar to kids with AS [74-80]. Interestingly, even with the robust motor deficit, normal sociability in a three-chambered social approach task was reported in $U b e 3 a^{m-/ p+}$ mice [70]. Learning and memory deficits were observed in ex vivo hippocampal slice long-term potentiation (LTP). LTP deficits specifically in the hippocampus indicated disruption of hippocampal calcium-calmodulin-dependent protein kinase II activity, which may result in decreased plasticity and learning and memory [81]. When this model was on the 129 background strain, it exhibited audiogenic-induced seizure susceptibility, that was background strain dependent [82-84], and abnormal EEG characteristics, including elevated delta frequency power, spiking activity and slow wave discharges, comparable to those seen clinically [85-87]. Moreover, sleep deficits such as reduced total sleep time, longer latencies to sleep onset and abnormal spindle production seen in the clinical population are consistently recapitulated in $U b e 3 a^{m-/ p+}$ mice, across strains [77]. Importantly, the exon- 2 deletion model is Ube $3 a$ specific, on a C57BL/6 J background strain and $[88,89]$ exhibits intact imprinting throughout the brain [90].

Another unique model is a reporter mouse that does not delete or mutate $U b e 3 a$, rather it inserts a visible tag via fusion of yellow fluorescent protein (YFP) to the c-terminus of E6-AP [91]. These YFP reporter mice allow for the visualization of $U b e 3 a$ from either the maternal or paternal copy. Reporter mice have become invaluable for translational neuroscience [92, 93].

\section{Rat Model of AS}

Recently, a rat model of AS was created using a CRISPR/ Cas9 system to delete the entire 90-kb Ube3a gene region $[76,78]$. Impairments in neonatal ultrasonic vocalizations and reflexes were detected. Adult rats exhibited motor and sensory deficits by reduced vertical activity in an open field assay, faster latencies to fall off of an accelerating rotarod, and longer times for adhesive removal. Learning and memory was diminished in the $U b e 3 a^{m-/ p+}$ animals compared to wildtype littermate controls on a pairwise discrimination touchscreen task. Lastly, deletion animals demonstrated reduced exploration to affiliative pro-social calls, suggesting lower social communication or social cognition, currently being explored further [76]. Genetically engineered rat models are becoming a widely feasible investigative approach for preclinical research, as they provide enhanced behavioral capabilities relative to mice and more analogous pharmacological properties to humans [94-98]. 


\section{Small Molecule Drugs in the Treatment of Angelman Syndrome}

Multiple small molecules are in clinical or pre-clinical development for Angelman syndrome. While precision therapy approaches may offer high future potential for disease-modifying treatment of genetically defined disorders, our understanding of these valuable therapies is relatively new. Indeed, at the time of writing, only two gene therapy products are currently FDA approved (Zolgensma ${ }^{\circledR}$ for spinal muscular atrophy with bi-allelic mutations in the SMN1 gene, and Luxturna ${ }^{\circledR}$ for bi-allelic RPE65 mutation-associated retinal dystrophy). Small molecule therapies, while not being disease modifying, can have great impact on specific symptom domains, such as seizures, having a major impact on quality of life. There is a large volume of preclinical and clinical knowledge around small molecule anticonvulsant drugs which can be leveraged for seizure control in AS.

\section{OV-101}

OV-101 is a small molecule extrasynaptic $\mathrm{GABA}_{\mathrm{A}}$ receptor agonist. It is also known as THIP (4,5,6,7-tetrahydroisoxazolo[5,4c]pyridin-3-ol) or gaboxadol. As compared to other GABAergic drugs such as benzodiazepines, which act on synaptic $\mathrm{GABA}_{\mathrm{A}}$ receptors mediating fast phasic inhibition, OV-101 acts specifically on extra-synaptic $\mathrm{GABA}_{\mathrm{A}}$ receptors [99]. These receptors are activated by ambient GABA levels and produce tonic inhibition - a consistent low amplitude hyperpolarizing current, which results in overall decreased excitability of neurons (for review, see [100]. There is evidence in AS animal models that tonic inhibition is impaired [101]. There is evidence that the underlying mechanism is decreased ubiquitin-mediated degradation of GAT1, leading to an excess of GAT1 mediated uptake of GABA [102], which reduces ambient GABA spillover required to activate extra-synaptic GABA receptors mediating tonic inhibition. This has been linked to phenotypes such as ataxia [102] and EEG abnormalities [103]. OV-101 aims to correct that deficit by increasing tonic inhibition in the brain.

Preclinically, OV-101 has been shown to improve tonic inhibitory deficits in slice preparations from AS mice [102, 103]. It was also seen to improve deficits in motor coordination, by the rotarod [102]. In clinical studies, promising phase 2 data showed improvements in a constellation of symptom domains including sleep, motor function, communication abilities, challenging behavior, and anxiety as assessed by the CGI-I [104]. Unfortunately, this failed to translate to any significant benefit over placebo in phase 3 , where OV-101 showed 0.7 point improvement compared to 0.8 point improvement in the placebo group (Ovid
Therapeutics press release). Development of OV-101 is currently on hold pending further analysis of the phase 3 data.

\section{Trofinetide NNZ-2566 and NNZ-2591}

Both trofinetide (NNZ-2566) and the follow-on molecule NNZ-2591 are small molecule IGF-1 mimetics. They activate PI3K-AKTt-mTOR and Ras-MAPK-ERK pathways and have been shown to increase synapse number and synaptic plasticity $[105,106]$. Spine numbers have been shown to be reduced in AS mouse models [91] and activity-dependent ERK phosphorylation and synaptic plasticity are impaired [107-110]. The therapeutic hypothesis is that through upregulating synaptic plasticity and synapse number, these compounds can have benefit in AS.

There are no preclinical studies published using AS models for these compounds. However, NNZ-2591 showed positive effects on memory in scopolamine challenged rats [111], and NNZ-2566 showed anticonvulsant effects in an ischemia model [112], suggesting that these compounds may have benefits on cognition and seizure control. IGF-1 and IGF-1 mimetics such as trofinetide are being pursued for a number of neurodevelopmental disorders [113]. IGF-1 was seen to improve defective AMPA receptor-mediated neurotransmission, LTP and improve motor performance in a Phelan-McDermid syndrome model [114]. IGF-2 has shown beneficial effects in AS mice, improving cognitive and motor deficits, and attenuating audiogenic seizures [115]. However, some caution should be taken in interpreting IGF-2 data in support of trofinetide and NNZ-2591, as this ligand shows some non-specificity in binding both the IGF-1 and IGF-2 receptors. Clinically, NNZ-2566/Trofinetide has shown some level of benefit in phase 2 studies in Rett syndrome [116] and fragile $X$ syndrome [117]. At the time of writing, NNZ-2591 has just completed a successful phase 1 trial, and clinical trials in AS are planned to start in 2021.

\section{Lovastatin}

Lovastatin was the first compound to be marketed in the statin class of compounds. These are HMG-CoA reductase inhibitors, with broad lipid-lowering effects, commonly prescribed for hypercholesterolemia. Lovastatin also acts to reduce RAS/ERK signaling $[118,119]$ and decrease protein synthesis via inhibition of cap-dependent translation [120]. There is general interest in the use of statins to treat a number of neurodevelopmental disorders (reviewed in detail in [121]). In AS, excessive levels of synaptic proteins have been seen [2], and so it can be hypothesized that decreasing protein synthesis by lovastatin could show clinical benefit. Lovastatin has been seen to have effects on seizure control and learning and attention in preclinical models of 
neurodevelopmental disorders [122, 123], so could potentially have effects on multiple symptom domains in AS. A large amount of literature was reviewed on statins in neurodevelopmental disorders [121].

In a preclinical study, lovastatin protected AS mice from audiogenic seizures, and reduced long burst firing in slices from these mice [124]. This suggests that there could be an anticonvulsant effect of lovastatin in AS. A related compound, simvastatin, also improved cognitive and social function in an AS mouse model. The authors related this effect to mechanistically restoring HDAC1/2 activity in these mice [125]. Clinically, lovastatin failed to improve outcome measures in neurofibromatosis type 1 [126] and fragile X [127] but no clinical study has yet been conducted in AS.

\section{Minocycline}

Minocycline is a tetracycline antibiotic which can be used to treat both gram-positive and gram-negative bacteria. Tetracycline antibiotics work by inhibiting protein synthesis [128], so could have potential benefit in AS by correcting excessive levels of synaptic proteins that have been spared ubiquitin mediated degradation. Minocycline also has activity as a matrix-metalloproteinase 9 (MMP9) inhibitor [129]. Studies in fragile $\mathrm{X}$ mice showed that minocycline increases the number of mature "mushroom" spines via its action as an MMP9 inhibitor [130]. Minocycline could be hypothesized to have a beneficial effect on synaptic morphology and plasticity in AS.

Clinically, Grieco et al. [131] showed some benefit in a small open-label trial in AS patients. However, a larger randomized placebo-controlled study revealed no benefit [132]. Subsequent work in a thorough in vivo test battery using AS mouse models also revealed no benefit of minocycline in AS preclinically [133].

\section{LB-100/PP2A Inhibitors}

LB-100 is a protein phosphatase 2A (PP2A) inhibitor. Recently, PP2A was shown to be overactive in Ube $3 \mathrm{a}^{\mathrm{m}-/ \mathrm{p}+}$ mice as a result of loss of ubiquitin-mediated degradation of PTPA, a PP2A activator [134]. The authors show that overexpression of this important regulator in neurons phenocopied spine deficits seen in Ube $3 \mathrm{a}^{\mathrm{m}-/ \mathrm{p}+}$ mice, and genetically reducing expression of PTPA corrected spine morphology deficits. Pharmacologically, the authors showed that directly inhibiting PP2A using tool small molecule LB-100 was able to reduce PP2A activity, rescue reduced mEPSC frequencies, and improve motor behavior on both the wire suspension and rotarod tasks. While LB-100 is a tool compound and not a therapeutic, PP2A inhibition as an approach is chemically tractable, and represents an interesting new pharmacological target for AS. However, given its ubiquitous tissue expression, and involvement in many cellular processes, it remains to be seen if this approach can be tailored to specifically benefit AS patients.

\section{BK Potassium Channel Inhibitors}

Sun et al. used a UBE3A-KO engineered human embryonic stem cell (hESC) model to demonstrate a biphasic effect on excitability, with KO neurons initially showing decreased spike frequency compared to wildtype neurons at low levels of current injection, but showing increased spike frequency at higher current levels $[135,136]$. They interpreted the data to suggest that the effect was mediated by increased BK channel currents compared to wildtype. The increase in BK channel current resulted from increased BK $\alpha$ subunit expression, due to decreased ubiquitin mediated degradation. Paxilline, a toxic alkaloid BK channel antagonist, was able to reduce the aberrantly increased BK channel current levels. The authors demonstrated that paxilline could also normalize network dynamics in a 3D organoid model. Paxilline also showed anticonvulsant effects in flurothyl and picrotoxin induced seizures in AS mice. While paxilline itself is toxic, BK channel inhibition could be further investigated as a potential treatment for seizures in AS. Consistent with this, paxilline has also shown to have anticonvulsant effects in picrotoxin and pentylenetetrazol (PTZ) induced seizures in wild-type mice [137]. This remains an exciting potential new therapeutic avenue for AS and is being evaluated preclinically as a component of the Foundation for Angelman Syndrome for Therapeutics (FAST) infrastructure award.

\section{Precision Therapies in the Treatment of Angelman Syndrome}

Gene therapy is simply the transfer of a therapeutic gene to treat a disease or disorder. This therapy can be performed ex vivo, in tissue collected then cultured in a lab, or in vivo, where the therapy is administered directly into the patient's body. Precision therapy offers hope for many single-gene diseases in which conventional treatment has failed. Because AS is caused by the loss of functional UBE3A, gene therapies designed to introduce a working $U B E 3 A$ copy or targeting the antisense silencing the maternal copy designed to reactivate the paternal allele are the most promising (Table 1). In 2019, GeneTx/Ultragenyx initiated a phase $1 / 2$ ASO clinical trial. Early data in five patients showed minimal toxicity at low doses and symptomatic improvement by caregiver impression (CGI) analysis (Berry-Kravis unpublished). Another ASO compound is also in phase I clinical trial (Roche NCT04428281). The ASO approach 
Table 1 The current stage of various therapeutics in development for Angelman syndrome

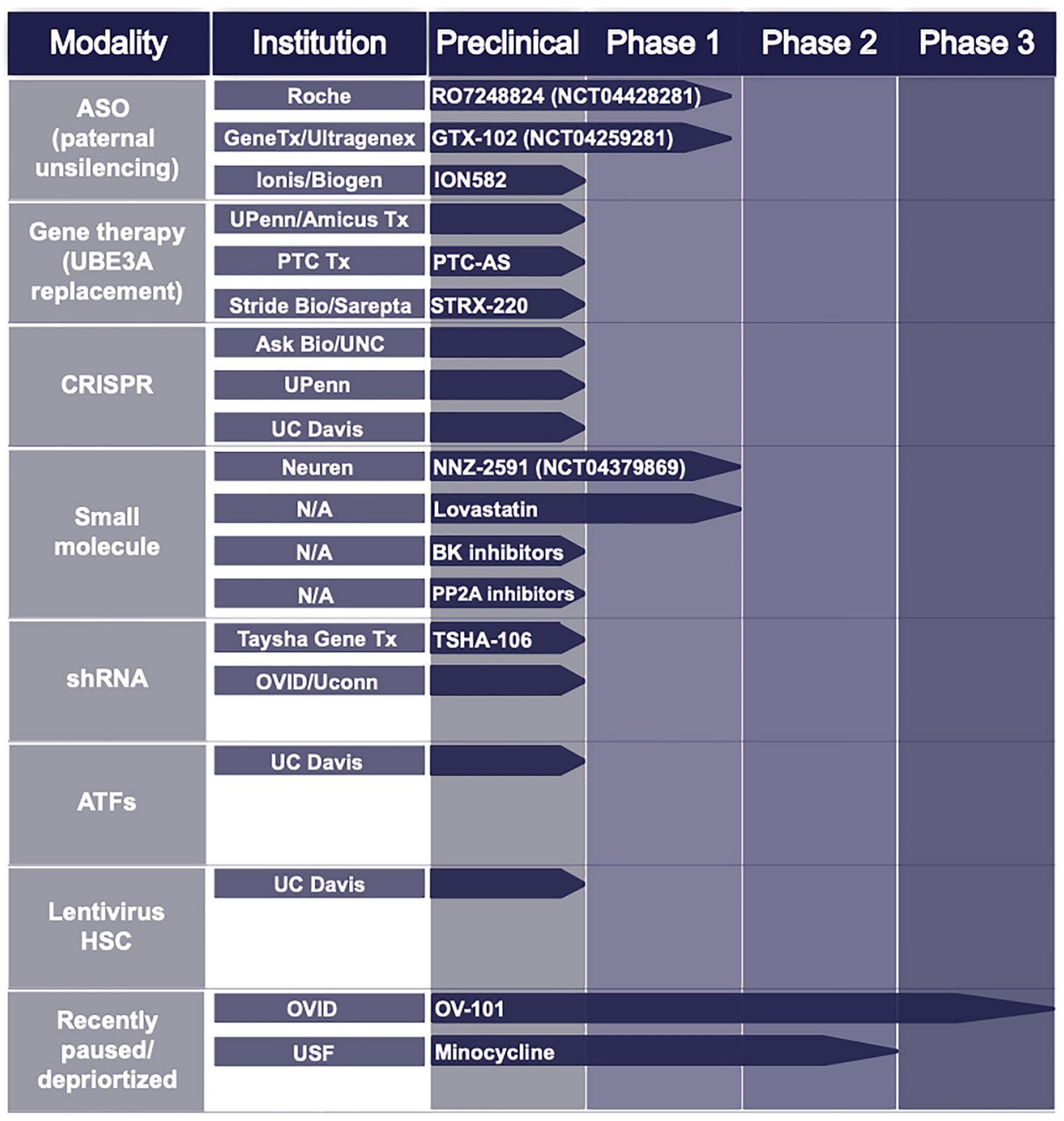

is extremely promising but has some potential limitations. Delivery is typically intrathecal, which for Angelman children would require full anesthesia. The anesthesia procedure carries its own risks, and would need to be repeated 3-4 times each year for the life of the individual.

\section{Therapies Targeted to Reactivate the Paternal UBE3A Allele by Suppressing UBE3A-ATS}

Several studies have indicated that paternal $U B E 3 A$ is silenced in neurons due to $U B E 3 A$-ATS [14, 20], and that suppression of the antisense transcript in cell and animal models results in the rescue of the phenotypic deficits reported $[55,138]$. In one of the first attempts to silence the Ube3a-ATS, topotecan, a topoisomerase I inhibitor, was administered to cortical neurons collected from embryonic day 15.5 neonates with paternally inherited $U b e 3 a$-YFP [139]. Topotecan reactivated the paternal allele (as seen by an increase in fluorescence of YFP) by inhibiting transcriptional progression of the ATS. Additionally, results indicated that the ligase function of Ube3a was restored indicating functional rescue. When injected unilaterally into the ventricle of mice with paternal Ube3a-YFP, paternal expression was observed in the treated hemisphere lasting up to 12 weeks. Although topotecan was approved by the FDA for various cancers including ovarian and lung cancer [140], its lack of specificity and general toxicity has limited the advancement of the drug to the clinic. While topotecan is not a viable treatment for $\mathrm{AS}$, this research paved the road for future studies focusing on paternal reactivation and highlighted the importance of specificity to a target gene.

Building from the topotecan results, one study aimed to reactivate the paternal allele by suppression of the $U b e 3 a$ ATS using a site-specific antisense oligonucleotide (ASO) approach [58]. ASO efficacy is dependent on (i) how well it targets the RNA of interest and (ii) construct modifications made directly to the ASO itself to prevent rapid degradation, promote affinity, and reduce toxicity. In this design, a phosphorothioate modified chimeric 2'-O-methoxyethyl DNA ASO was designed complementary to a region of 
mouse Ube3a-ATS downstream of SNRPN. After nuclear hybridization of the ASO to the ATS RNA, the Ube3a-ATS is cleaved and subsequently degraded. When the ASO was administered via a unilateral intracerebroventricular injection into a paternally inherited Ube $3 a$-YFP mouse, paternal expression was reinstated for 4 months. Additionally, exon 2 deletion $U b e 3 a^{m-/ p+}$ mice treated with the ASO exhibited rescue of contextual fear conditioning deficits and excessive weight gain, albeit weight gain is not a translational phenotype in AS. To date, this is the only reported ASO used in an AS model, but with the progression of ASOs across clinical trials [141], it is expected that this will be a prominent therapeutic focus in future studies.

Various other engineered DNA-binding proteins such as zinc finger-based artificial transcription factors (ZincATF), transcription activator-like effector-based artificial transcription factors (TALEs), and clustered regularly interspaced short palindromic repeat (CRISPR/Cas9) systems have been considered or studied as a tool to reactivate the paternal allele in AS [31]. Both Zinc-ATFs and TALEs use amino acid side chains to recognize DNA base pairs. These compounds activate or suppress a gene of interest by regulating its transcription. TALEs are more diverse in the spectrum of sequences they can target, but Zinc-ATFs have been more comprehensively studied and are therefore preferred in gene therapy design. A Zinc-ATF protein has been constructed and tested in an animal model of AS, with promising results $[56,57]$. The construct was designed to target a site slightly upstream of SNRPN, and both subcutaneous and intraperitoneal injections resulted in widespread $U b e 3 a$ expression in $U b e 3 a^{-/ p+}$ mice $[56,57]$. Molecular therapies such as these are promising, but not yet feasible as therapeutic options due to the need for continued re-administration and lack of an optimized delivery method. Recently, two publications regarding the use of CRISPR/Cas9 nuclease to disrupt the Ube3a-ATS were described [142, 143]. In both studies, guide RNAs were used to target nuclease activity to a site-specific region of the region between Snord115. CRISPR/Cas9 is advantageous in its specificity and ease of site targeting using guide RNAs. While the targeting loci differed between the groups with the paper by Schmid et. al. designed to cause a single INDEL between Snord115 and Ube $3 a 3^{\prime}$ UTR and the paper by Wolter et. al. designed to target approximately 75 regions of the Snord115 cluster, both approaches disrupt Ube3a-ATS without affecting Snrpn or Snord116 expression [142, 143]. Both strategies utilized AAV gene therapy for delivery of the Cas9 nuclease and guide RNA constructs. The Schmid group performed neonatal delivery and observed robust transduction efficiency and Ube $3 a$ upregulation. In utero injections were performed in the Wolter study with similar transduction efficiency and increased levels of Ube3a. Both studies utilized a variety of behavioral, anatomical, and functional assessments including body weight, brain size, open field, marble burying, nest building, open field and latency to fall on the rotarod task. In both studies, functional rescue was observed on multiple behavioral domains albeit on different tasks. These two manuscripts both represent the first in vivo nuclease use of Cas9 in the brain of an AS mouse model. While more work is needed to understand the optimal age of intervention, "optimal" translational outcome measures, and further studies on the safety and toxicity of this approach, they both present promising avenues to disrupt Ube3a-ATS and drive expression of $U b e 3 a$ from the paternal allele.

\section{Therapies Designed to Introduce a Functional Copy of UBE3A}

Given that AS is a single-gene disorder, resulting from the loss of UBE3A activity in the brain, another practical gene therapy approach would be to introduce functioning $U B E 3 A$ into affected cells. This approach has been attempted by injecting an adeno-associated virus (AAV) carrying Ube $3 a$ into the hippocampus of Ube3a-deficient mice [144]. The treatment resulted in localized reinstatement of Ube 3 a to wild-type levels and rescue of the LTP deficit previously reported. Behaviorally, contextual fear conditioning and Morris water-maze impairments were also restored to that of wildtype littermate controls, supplementing the LTP finding and suggesting this treatment was effective for learning and memory. Motor deficiencies, measured by latency to fall off an accelerating rotarod and exploratory behavior in a novel field, were not improved. Anxiety-like behavior, measured by elevated plus-maze, also showed no treatment effect. The lack of improvement on these measures may be due to the limited distribution of the AAV throughout the hippocampus.

In a more recent study, modified autologous hematopoietic stem and progenitor cells with a lentiviral vector expressing $U B E 3 A$ were introduced into immunocompromised $U b e 3 a^{m-/ p+}$ mice to provide functional UBE3A via cross correction [75]. This treatment resulted in behavioral rescue of several motor assays including open field, beam walking, rotarod, gait outcomes, including stride width, stride frequency and stance. Additionally, cognitive improvements were observed in novel object recognition and the persistent electrophysiological characteristic of elevated delta power typically seen in AS individuals and $U b e 3 a^{m-/ p+}$ mice and rats $[77,85,86$, 145-147] were reduced to that of wild-type levels. Of particular importance, all behavioral rescue was observed in both neonatal and adult treated mice, providing promising work for future cross correction type work in single gene disorders. 


\section{Challenges in Designing a Precision Medicine for Angelman Syndrome}

While targeted gene therapies offer many advantages in the treatment of AS, there are still challenges to be discussed when utilizing these methods. The ideal gene therapy for AS would be specific to UBE3A, minimally invasive, nontoxic, restore UBE3A to normal endogenous levels, and be effective at various developmental timepoints. One of the largest roadblocks faced in therapeutic development is delivery.

Delivery of a gene therapy to the required site is a challenge encountered universally. Given that AS is a CNSspecific disorder, delivery must be able to cross the BBB or be administered intracranially or intrathecally. Intracranial injections are invasive and generally not customary for a non-lethal disorder; therefore, intrathecal or peripheral administration are at the center in gene therapy design. Attention must be paid to the delivery vehicle as well (viral vectors, stem cells, liposomes, etc.) to reduce possible oncogenic or immune activation effects such as those seen in AAV research [148].

Another challenge a gene therapy designed for AS is that of gene dose. Maternally derived duplications or triplications of 15q11.2-q13.3 are the most penetrant genomic rearrangements observed in individuals with ASD, accounting for up to $3 \%$ of ASD cases, and indicated in/ responsible for Dup15q syndrome [149-151]. Pronounced clinical features associated with Dup15q syndrome are intellectual disability, seizures, anxiety, global developmental delay, hypotonia, speech impairments, motor coordination, and minor dysmorphic features [152-154]. While it has been reported that imprinting does not reduce the amount of UBE3A in neurons [155], it will be important to ensure that paternal reactivation or UBE3A/UBE3A reintroduction does not overexpress the gene.

Finally, the time point of a treatment is critical in a developmental disorder such as AS. Ideally, the hope is to treat as early as possible, but a therapy for all ages is essential. Previous rodent work has shown that a loss of Ube $3 a$ in early embryonic development resulted in predictable AS behavioral phenotypes while either juvenile or adult loss of Ube $3 a$ had fewer, lessened behavioral deficits, suggesting the importance of Ube $3 a$ reinstatement earlier in life $[156,157]$. These studies have led to the discussion of prenatal treatment for AS [158], but this can be an invasive and dangerous suggestion especially when the severity of symptoms vary by individual. It is unclear what symptoms may be alleviated by various treatments given at different developmental timepoints. In fact, in a recent publication, using hematopetic stem cells to introduce a Ube3a-expressing lentiviral vector illustrated behavioural rescue of motor, cognitive and neurophysiological AS phenotypes following adult and neonatal-treated animals [75]. This design known as "cross correction" has been proven safe in other disorders, and is currently in IND review with the FDA. Other work by a collaborating group found adult rescue of AS behavioral phenotypes following systemic treatment with an artificial transcription factor (ATF) [56, 57] and yet another laboratory was successful with viral delivery of Ube3a [144].

\section{Conclusion}

Here, we review the Angelman Syndrome, the causal gene, $U B E 3 A$, animal models of AS, emerging genetic, stem cell and precision medicine therapies and associated challenges faced in bench to bedside pipeline. Currently, there is no cure for AS and the treatments available are only useful in mitigating and managing a few of the symptoms throughout a patient's lifetime. Gene and molecular precision therapies offer a promising glimpse into the future of precision-medicine and work in this field will likely pave the road toward therapeutic development for other singlegene disorders.

Supplementary Information The online version contains supplementary material available at https://doi.org/10.1007/s13311-021-01082-x.

Required Author Forms Disclosure forms provided by the authors are available with the online version of this article.

Open Access This article is licensed under a Creative Commons Attribution 4.0 International License, which permits use, sharing, adaptation, distribution and reproduction in any medium or format, as long as you give appropriate credit to the original author(s) and the source, provide a link to the Creative Commons licence, and indicate if changes were made. The images or other third party material in this article are included in the article's Creative Commons licence, unless indicated otherwise in a credit line to the material. If material is not included in the article's Creative Commons licence and your intended use is not permitted by statutory regulation or exceeds the permitted use, you will need to obtain permission directly from the copyright holder. To view a copy of this licence, visit http://creativecommons.org/licenses/by/4.0/.

\section{References}

1. Williams CA, Driscoll DJ, Dagli AI. Clinical and genetic aspects of Angelman syndrome. Genet Med. 2010;12(7):385-95.

2. Margolis SS, Sell GL, Zbinden MA, Bird LM. Angelman Syndrome. Neurotherapeutics. 2015;12(3):641-50.

3. Bonello D, Camilleri F, Calleja-Agius J. Angelman Syndrome: Identification and Management. Neonatal Netw. 2017;36(3):142-51.

4. Williams CA, Beaudet AL, Clayton-Smith J, Knoll JH, Kyllerman M, Laan LA, et al. Angelman syndrome 2005: updated consensus for diagnostic criteria. Am J Med Genet A. 2006;140(5):413-8. 
5. Thibert RL, Conant KD, Braun EK, Bruno P, Said RR, Nespeca MP, et al. Epilepsy in Angelman syndrome: a questionnairebased assessment of the natural history and current treatment options. Epilepsia. 2009;50(11):2369-76.

6. Uemura N, Matsumoto A, Nakamura M, Watanabe K, Negoro T, Kumagai T, et al. Evolution of seizures and electroencephalographical findings in 23 cases of deletion type Angelman syndrome. Brain Dev. 2005;27(5):383-8.

7. Khan N, Cabo R, Tan WH, Tayag R, Bird LM. Healthcare burden among individuals with Angelman syndrome: Findings from the Angelman Syndrome Natural History Study. Mol Genet Genomic Med. 2019;7(7):e00734.

8. Kishino T, Lalande M, Wagstaff J. UBE3A/E6-AP mutations cause Angelman syndrome. Nat Genet. 1997;15(1):70-3.

9. Matsuura T, Sutcliffe JS, Fang P, Galjaard RJ, Jiang YH, Benton CS, et al. De novo truncating mutations in E6-AP ubiquitin-protein ligase gene (UBE3A) in Angelman syndrome. Nat Genet. 1997;15(1):74-7.

10. Wagstaff J, Knoll JH, Glatt KA, Shugart YY, Sommer A, Lalande M. Maternal but not paternal transmission of 15q11-13-linked nondeletion Angelman syndrome leads to phenotypic expression. Nat Genet. 1992;1(4):291-4.

11. Sutcliffe JS, Jiang YH, Galijaard RJ, Matsuura T, Fang P, Kubota $\mathrm{T}$, et al. The E6-Ap ubiquitin-protein ligase (UBE3A) gene is localized within a narrowed Angelman syndrome critical region. Genome Res. 1997;7(4):368-77.

12. Albrecht U, Sutcliffe JS, Cattanach BM, Beechey CV, Armstrong D, Eichele G, et al. Imprinted expression of the murine Angelman syndrome gene, Ube3a, in hippocampal and Purkinje neurons. Nat Genet. 1997;17(1):75-8.

13. $\mathrm{Vu} \mathrm{TH}, \mathrm{Hoffman} \mathrm{AR}$. Imprinting of the Angelman syndrome gene, UBE3A, is restricted to brain. Nat Genet. 1997;17(1):12-3.

14. Rougeulle $\mathrm{C}$, Glatt $\mathrm{H}$, Lalande $\mathrm{M}$. The Angelman syndrome candidate gene, UBE3A/E6-AP, is imprinted in brain. Nat Genet. 1997;17(1):14-5.

15. Yamasaki K, Joh K, Ohta T, Masuzaki H, Ishimaru T, Mukai $\mathrm{T}$, et al. Neurons but not glial cells show reciprocal imprinting of sense and antisense transcripts of Ube3a. Hum Mol Genet. 2003;12(8):837-47.

16. Chamberlain SJ, Brannan CI. The Prader-Willi syndrome imprinting center activates the paternally expressed murine Ube3a antisense transcript but represses paternal Ube3a. Genomics. 2001;73(3):316-22.

17. Runte M, Huttenhofer A, Gross S, Kiefmann M, Horsthemke B, Buiting K. The IC-SNURF-SNRPN transcript serves as a host for multiple small nucleolar RNA species and as an antisense RNA for UBE3A. Hum Mol Genet. 2001;10(23):2687-700.

18. Fang P, Lev-Lehman E, Tsai TF, Matsuura T, Benton CS, Sutcliffe JS, et al. The spectrum of mutations in UBE3A causing Angelman syndrome. Hum Mol Genet. 1999;8(1):129-35.

19. Sadikovic B, Fernandes P, Zhang VW, Ward PA, Miloslavskaya I, Rhead W, et al. Mutation Update for UBE3A variants in Angelman syndrome. Hum Mutat. 2014;35(12):1407-17.

20. Jiang Y, Lev-Lehman E, Bressler J, Tsai TF, Beaudet AL. Genetics of Angelman syndrome. Am J Hum Genet. 1999;65(1):1-6.

21. Beaudet AL. Angelman syndrome: Drugs to awaken a paternal gene. Nature. 2011;481(7380):150-2.

22. Malpass K. Neurodevelopmental disorders: Unsilencing dormant Ube3a--hope for Angelman syndrome? Nat Rev Neurol. 2012;8(2):62.

23. Reiter LT, Seagroves TN, Bowers M, Bier E. Expression of the Rho-GEF Pbl/ECT2 is regulated by the UBE3A E3 ubiquitin ligase. Hum Mol Genet. 2006;15(18):2825-35.

24. Wu Y, Bolduc FV, Bell K, Tully T, Fang Y, Sehgal A, et al. A Drosophila model for Angelman syndrome. Proc Natl Acad Sci U S A. 2008;105(34):12399-404.
25. Jiang $\mathrm{YH}$, Armstrong D, Albrecht U, Atkins CM, Noebels $\mathrm{JL}$, Eichele G, et al. Mutation of the Angelman ubiquitin ligase in mice causes increased cytoplasmic p53 and deficits of contextual learning and long-term potentiation. Neuron. 1998;21(4):799-811.

26. Sato M. Early Origin and Evolution of the Angelman Syndrome Ubiquitin Ligase Gene Ube3a. Front Cell Neurosci. 2017;11:62.

27. Jana NR. Understanding the pathogenesis of Angelman syndrome through animal models. Neural Plast. 2012;2012:710943.

28. Riemens RJM, Soares ES, Esteller M, Delgado-Morales R. Stem Cell Technology for (Epi)genetic Brain Disorders. Adv Exp Med Biol. 2017;978:443-75.

29. Beaudet AL, Meng L. Gene-targeting pharmaceuticals for singlegene disorders. Hum Mol Genet. 2016;25(R1):R18-26.

30. Tan WH, Bird LM. Angelman syndrome: Current and emerging therapies in 2016. Am J Med Genet C Semin Med Genet. 2016;172(4):384-401.

31. Bailus BJ, Segal DJ. The prospect of molecular therapy for Angelman syndrome and other monogenic neurologic disorders. BMC Neurosci. 2014;15:76.

32. Huibregtse JM, Scheffner M, Howley PM. A cellular protein mediates association of p53 with the E6 oncoprotein of human papillomavirus types 16 or 18. EMBO J. 1991;10(13):4129-35.

33. Yamamoto Y, Huibregtse JM, Howley PM. The human E6-AP gene (UBE3A) encodes three potential protein isoforms generated by differential splicing. Genomics. 1997;41(2):263-6.

34. Dagli A, Buiting K, Williams CA. Molecular and Clinical Aspects of Angelman Syndrome. Mol Syndromol. 2012;2(3-5):100-12.

35. Scheffner M, Nuber U, Huibregtse JM. Protein ubiquitination involving an E1-E2-E3 enzyme ubiquitin thioester cascade. Nature. 1995;373(6509):81-3.

36. Huang L, Kinnucan E, Wang G, Beaudenon S, Howley PM, Huibregtse JM, et al. Structure of an E6AP-UbcH7 complex: insights into ubiquitination by the E2-E3 enzyme cascade. Science. 1999;286(5443):1321-6.

37. Tomaic V, Banks L. Angelman syndrome-associated ubiquitin ligase UBE3A/E6AP mutants interfere with the proteolytic activity of the proteasome. Cell Death Dis. 2015;6:e1625.

38. Nawaz Z, Lonard DM, Smith CL, Lev-Lehman E, Tsai SY, Tsai MJ, et al. The Angelman syndrome-associated protein, E6-AP, is a coactivator for the nuclear hormone receptor superfamily. Mol Cell Biol. 1999;19(2):1182-9.

39. El Hokayem J, Nawaz Z. E6AP in the brain: one protein, dual function, multiple diseases. Mol Neurobiol. 2014;49(2):827-39.

40. Cooper EM, Hudson AW, Amos J, Wagstaff J, Howley PM. Biochemical analysis of Angelman syndrome-associated mutations in the E3 ubiquitin ligase E6-associated protein. J Biol Chem. 2004;279(39):41208-17.

41. Martinez-Noel G, Galligan JT, Sowa ME, Arndt V, Overton TM, Harper JW, et al. Identification and proteomic analysis of distinct UBE3A/E6AP protein complexes. Mol Cell Biol. 2012:32(15):3095-106.

42. Martinez-Noel G, Luck K, Kuhnle S, Desbuleux A, Szajner P, Galligan JT, et al. Network Analysis of UBE3A/E6AP-Associated Proteins Provides Connections to Several Distinct Cellular Processes. J Mol Biol. 2018;430(7):1024-50.

43. Ramirez J, Lectez B, Osinalde N, Siva M, Elu N, Aloria K, et al. Quantitative proteomics reveals neuronal ubiquitination of Rngo/ Ddi1 and several proteasomal subunits by Ube3a, accounting for the complexity of Angelman syndrome. Hum Mol Genet. 2018;27(11):1955-71.

44. Nuber U, Schwarz SE, Scheffner M. The ubiquitin-protein ligase E6-associated protein (E6-AP) serves as its own substrate. Eur J Biochem. 1998;254(3):643-9. 
45. Lopez SJ, Dunaway K, Islam MS, Mordaunt C, Vogel Ciernia A, Meguro-Horike M, et al. UBE3A-mediated regulation of imprinted genes and epigenome-wide marks in human neurons. Epigenetics. 2017;12(11):982-90.

46. Germain ND, Chen PF, Plocik AM, Glatt-Deeley H, Brown J, Fink JJ, et al. Gene expression analysis of human induced pluripotent stem cell-derived neurons carrying copy number variants of chromosome 15q11-q13.1. Mol Autism. 2014;5:44.

47. Burette AC, Judson MC, Li AN, Chang EF, Seeley WW, Philpot $\mathrm{BD}$, et al. Subcellular organization of UBE3A in human cerebral cortex. Mol Autism. 2018;9:54.

48. Reik W, Walter J. Genomic imprinting: parental influence on the genome. Nat Rev Genet. 2001;2(1):21-32.

49. LaSalle JM, Reiter LT, Chamberlain SJ. Epigenetic regulation of UBE3A and roles in human neurodevelopmental disorders. Epigenomics. 2015;7(7):1213-28.

50. Lalande M, Calciano MA. Molecular epigenetics of Angelman syndrome. Cell Mol Life Sci. 2007;64(7-8):947-60.

51. Landers M, Bancescu DL, Le Meur E, Rougeulle C, GlattDeeley H, Brannan C, et al. Regulation of the large (approximately $1000 \mathrm{~kb}$ ) imprinted murine Ube3a antisense transcript by alternative exons upstream of Snurf/Snrpn. Nucleic Acids Res. 2004;32(11):3480-92.

52. Meng L, Person RE, Beaudet AL. Ube3a-ATS is an atypical RNA polymerase II transcript that represses the paternal expression of Ube3a. Hum Mol Genet. 2012;21(13):3001-12.

53. Pelechano V, Steinmetz LM. Gene regulation by antisense transcription. Nat Rev Genet. 2013;14(12):880-93.

54. Chamberlain SJ, Lalande M. Angelman syndrome, a genomic imprinting disorder of the brain. J Neurosci. 2010;30(30):9958-63.

55. Meng L, Person RE, Huang W, Zhu PJ, Costa-Mattioli M, Beaudet AL. Truncation of Ube3a-ATS unsilences paternal Ube3a and ameliorates behavioral defects in the Angelman syndrome mouse model. PLoS Genet. 2013;9(12):e1004039.

56. Bailus BJ, Pyles B, McAlister MM, O'Geen H, Lockwood SH, Adams AN, et al. Protein Delivery of an Artificial Transcription Factor Restores Widespread Ube3a Expression in an Angelman Syndrome Mouse Brain. Mol Ther. 2016;24(3):548-55.

57. Pyles B, Bailus BJ, O'Geen H, Segal DJ. Purified Protein Delivery to Activate an Epigenetically Silenced Allele in Mouse Brain. Methods Mol Biol. 2018;1767:227-39.

58. Meng L, Ward AJ, Chun S, Bennett CF, Beaudet AL, Rigo F. Towards a therapy for Angelman syndrome by targeting a long non-coding RNA. Nature. 2015;518(7539):409-12.

59. Peters SU, Bird LM, Kimonis V, Glaze DG, Shinawi LM, Bichell TJ, et al. Double-blind therapeutic trial in Angelman syndrome using betaine and folic acid. Am J Med Genet A. 2010;152A(8): 1994-2001.

60. Bird LM, Tan WH, Bacino CA, Peters SU, Skinner SA, Anselm I, et al. A therapeutic trial of pro-methylation dietary supplements in Angelman syndrome. Am J Med Genet A. 2011;155A(12):2956-63.

61. Chamberlain SJ, Chen PF, Ng KY, Bourgois-Rocha F, LemtiriChlieh F, Levine ES, et al. Induced pluripotent stem cell models of the genomic imprinting disorders Angelman and Prader-Willi syndromes. Proc Natl Acad Sci U S A. 2010;107(41):17668-73.

62. Stanurova J, Neureiter A, Hiber M, de Oliveira Kessler H, Stolp K, Goetzke R, et al. Angelman syndrome-derived neurons display late onset of paternal UBE3A silencing. Sci Rep. 2016;6:30792.

63. Fink JJ, Robinson TM, Germain ND, Sirois CL, Bolduc KA, Ward AJ, et al. Disrupted neuronal maturation in Angelman syndrome-derived induced pluripotent stem cells. Nat Commun. 2017;8:15038.
64. Hsiao JS, Germain ND, Wilderman A, Stoddard C, Wojenski LA, Villafano GJ, et al. A bipartite boundary element restricts UBE3A imprinting to mature neurons. Proc Natl Acad Sci U S A. 2019;116(6):2181-6.

65. Cattanach BM, Barr JA, Beechey CV, Martin J, Noebels J, Jones $\mathrm{J}$. A candidate model for Angelman syndrome in the mouse. Mamm Genome. 1997;8(7):472-8.

66. Miura K, Kishino T, Li E, Webber H, Dikkes P, Holmes GL, et al. Neurobehavioral and electroencephalographic abnormalities in Ube3a maternal-deficient mice. Neurobiol Dis. 2002;9(2):149-59.

67. Jiang YH, Pan Y, Zhu L, Landa L, Yoo J, Spencer C, et al. Altered ultrasonic vocalization and impaired learning and memory in Angelman syndrome mouse model with a large maternal deletion from Ube3a to Gabrb3. PLoS One. 2010;5(8):e12278.

68. van Woerden GM, Harris KD, Hojjati MR, Gustin RM, Qiu S, de Avila Freire R, et al. Rescue of neurological deficits in a mouse model for Angelman syndrome by reduction of alphaCaMKII inhibitory phosphorylation. Nat Neurosci. 2007;10(3):280-2.

69. Mulherkar SA, Jana NR. Loss of dopaminergic neurons and resulting behavioural deficits in mouse model of Angelman syndrome. Neurobiol Dis. 2010;40(3):586-92.

70. Allensworth M, Saha A, Reiter LT, Heck DH. Normal social seeking behavior, hypoactivity and reduced exploratory range in a mouse model of Angelman syndrome. BMC Genet. 2011;12:7.

71. Godavarthi SK, Dey P, Maheshwari M, Jana NR. Defective glucocorticoid hormone receptor signaling leads to increased stress and anxiety in a mouse model of Angelman syndrome. Hum Mol Genet. 2012;21(8):1824-34.

72. Riday TT, Dankoski EC, Krouse MC, Fish EW, Walsh PL, Han JE, et al. Pathway-specific dopaminergic deficits in a mouse model of Angelman syndrome. J Clin Invest. 2012;122(12):4544-54.

73. Miao S, Chen R, Ye J, Tan GH, Li S, Zhang J, et al. The Angelman syndrome protein Ube3a is required for polarized dendrite morphogenesis in pyramidal neurons. J Neurosci. 2013;33(1):327-33.

74. Grieco JC, Gouelle A, Weeber EJ. Identification of spatiotemporal gait parameters and pressure-related characteristics in children with Angelman syndrome: A pilot study. J Appl Res Intellect Disabil. 2018;31(6):1219-24.

75. Adhikari A, Copping NA, Beegle J, Cameron DL, Deng P, $\mathrm{O}^{\prime}$ Geen $\mathrm{H}$, et al. Functional rescue in an Angelman syndrome model following treatment with lentivector transduced hematopoietic stem cells. Hum Mol Genet. 2021;30(12):1067-83.

76. Berg EL, Pride MC, Petkova SP, Lee RD, Copping NA, Shen $\mathrm{Y}$, et al. Translational outcomes in a full gene deletion of ubiquitin protein ligase E3A rat model of Angelman syndrome. Transl Psychiatry. 2020;10(1):39.

77. Copping NA, Silverman JL. Abnormal electrophysiological phenotypes and sleep deficits in a mouse model of Angelman Syndrome. Mol Autism. 2021;12(1):9.

78. Dodge A, Peters MM, Greene HE, Dietrick C, Botelho R, Chung D, et al. Generation of a Novel Rat Model of Angelman Syndrome with a Complete Ube3a Gene Deletion. Autism Res. 2020;13(3):397-409.

79. SP P, JD D, JL S. Gait as a Rigorous Translational Outcome Measure in Angelman Syndrome: Implications for Preclinical Models of Neurodevelopmental Disorders Autism Research. 2021 (In press).

80. A S, SP P, JL S, JD D. Multiple Novel Measures of Motor Patterning Offer Insight into the Natural History of Angelman Syndrome Journal of Medical Genetics 2021 (In Press).

81. Weeber EJ, Jiang YH, Elgersma Y, Varga AW, Carrasquillo Y, Brown SE, et al. Derangements of hippocampal calcium/ calmodulin-dependent protein kinase II in a mouse model 
for Angelman mental retardation syndrome. J Neurosci. 2003;23(7):2634-44.

82. Born HA, Dao AT, Levine AT, Lee WL, Mehta NM, Mehra S, et al. Strain-dependence of the Angelman Syndrome phenotypes in Ube3a maternal deficiency mice. Sci Rep. 2017;7(1):8451.

83. Huang HS, Burns AJ, Nonneman RJ, Baker LK, Riddick NV, Nikolova VD, et al. Behavioral deficits in an Angelman syndrome model: effects of genetic background and age. Behav Brain Res. 2013;243:79-90.

84. Copping and Silverman Molecular Autism (2021) 12:9. https:// doi.org/10.1186/s13229-021-00416-y

85. Sidorov MS, Deck GM, Dolatshahi M, Thibert RL, Bird LM, $\mathrm{Chu} \mathrm{CJ}$, et al. Delta rhythmicity is a reliable EEG biomarker in Angelman syndrome: a parallel mouse and human analysis. J Neurodev Disord. 2017;9:17.

86. Frohlich J, Miller MT, Bird LM, Garces P, Purtell H, Hoener MC, et al. Electrophysiological Phenotype in Angelman Syndrome Differs Between Genotypes. Biol Psychiatry. 2019;85(9):752-9.

87. Pelc K, Boyd SG, Cheron G, Dan B. Epilepsy in Angelman syndrome. Seizure. 2008;17(3):211-7.

88. Burette AC, Judson MC, Burette S, Phend KD, Philpot BD, Weinberg RJ. Subcellular organization of UBE3A in neurons. $\mathrm{J}$ Comp Neurol. 2016.

89. Judson MC, Sosa-Pagan JO, Del Cid WA, Han JE, Philpot BD. Allelic specificity of Ube 3 a expression in the mouse brain during postnatal development. J Comp Neurol. 2014;522(8):1874-96.

90. Jones KA, Han JE, DeBruyne JP, Philpot BD. Persistent neuronal Ube3a expression in the suprachiasmatic nucleus of Angelman syndrome model mice. Sci Rep. 2016;6:28238.

91. Dindot SV, Antalffy BA, Bhattacharjee MB, Beaudet AL. The Angelman syndrome ubiquitin ligase localizes to the synapse and nucleus, and maternal deficiency results in abnormal dendritic spine morphology. Hum Mol Genet. 2008;17(1):111-8.

92. Jiang T, Xing B, Rao J. Recent developments of biological reporter technology for detecting gene expression. Biotechnol Genet Eng Rev. 2008;25:41-75.

93. Tsien RY. The green fluorescent protein. Annu Rev Biochem. 1998;67:509-44.

94. Frankel WN. Of rats, mice, and men? Nat Genet. 1995;9(1):3-4.

95. Geurts AM, Cost GJ, Freyvert Y, Zeitler B, Miller JC, Choi VM, et al. Knockout rats via embryo microinjection of zinc-finger nucleases. Science. 2009;325(5939):433.

96. Abbott A. Return of the rat. Nature. 2009;460(7257):788.

97. Abbott A. Neuroscience: The rat pack. Nature. 2010;465(7296):282-3.

98. Ellenbroek B, Youn J. Rodent models in neuroscience research: is it a rat race? Dis Model Mech. 2016;9(10):1079-87.

99. Meera P, Wallner M, Otis TS. Molecular basis for the high THIP/ gaboxadol sensitivity of extrasynaptic GABA(A) receptors. J Neurophysiol. 2011;106(4):2057-64.

100. Zheleznova NN, Sedelnikova A, Weiss DS. Function and modulation of delta-containing GABA(A) receptors. Psychoneuroendocrinology. 2009;34 Suppl 1:S67-73.

101. Bruinsma CF, Schonewille M, Gao Z, Aronica EM, Judson MC, Philpot BD, et al. Dissociation of locomotor and cerebellar deficits in a murine Angelman syndrome model. J Clin Invest. 2015;125(11):4305-15.

102. Egawa K, Kitagawa K, Inoue K, Takayama M, Takayama C, Saitoh $\mathrm{S}$, et al. Decreased tonic inhibition in cerebellar granule cells causes motor dysfunction in a mouse model of Angelman syndrome. Sci Transl Med. 2012;4(163):163ra57.

103. Judson MC, Wallace ML, Sidorov MS, Burette AC, Gu B, van Woerden GM, et al. GABAergic Neuron-Specific Loss of Ube3a Causes Angelman Syndrome-Like EEG Abnormalities and Enhances Seizure Susceptibility. Neuron. 2016;90(1):56-69.

104. Bird LM, Ochoa-Lubinoff C, Tan WH, Heimer G, Melmed RD, Rakhit A, et al. The STARS Phase 2 Study: A Randomized
Controlled Trial of Gaboxadol in Angelman Syndrome. Neurology. 2021;96(7):e1024-e35.

105. Guan J, Harris P, Brimble M, Lei Y, Lu J, Yang Y, et al. The role for IGF-1-derived small neuropeptides as a therapeutic target for neurological disorders. Expert Opin Ther Targets. 2015;19(6):785-93.

106. Dyer AH, Vahdatpour C, Sanfeliu A, Tropea D. The role of Insulin-Like Growth Factor 1 (IGF-1) in brain development, maturation and neuroplasticity. Neuroscience. 2016;325:89-99.

107. Filonova I, Trotter JH, Banko JL, Weeber EJ. Activity-dependent changes in MAPK activation in the Angelman Syndrome mouse model. Learn Mem. 2014;21(2):98-104.

108. Greer PL, Hanayama R, Bloodgood BL, Mardinly AR, Lipton DM, Flavell SW, et al. The Angelman Syndrome protein Ube3A regulates synapse development by ubiquitinating arc. Cell. 2010;140(5):704-16.

109. Sato M, Stryker MP. Genomic imprinting of experience-dependent cortical plasticity by the ubiquitin ligase gene Ube3a. Proc Natl Acad Sci U S A. 2010;107(12):5611-6.

110. Yashiro K, Riday TT, Condon KH, Roberts AC, Bernardo DR, Prakash R, et al. Ube3a is required for experience-dependent maturation of the neocortex. Nat Neurosci. 2009;12(6):777-83.

111. Guan J, Zhang R, Dale-Gandar L, Hodgkinson S, Vickers MH. NNZ-2591, a novel diketopiperazine, prevented scopolamineinduced acute memory impairment in the adult rat. Behav Brain Res. 2010;210(2):221-8.

112. Lu XC, Si Y, Williams AJ, Hartings JA, Gryder D, Tortella FC. NNZ-2566, a glypromate analog, attenuates brain ischemiainduced non-convulsive seizures in rats. J Cereb Blood Flow Metab. 2009;29(12):1924-32.

113. Vahdatpour C, Dyer AH, Tropea D. Insulin-Like Growth Factor 1 and Related Compounds in the Treatment of Childhood-Onset Neurodevelopmental Disorders. Front Neurosci. 2016;10:450.

114. Bozdagi O, Tavassoli T, Buxbaum JD. Insulin-like growth factor-1 rescues synaptic and motor deficits in a mouse model of autism and developmental delay. Mol Autism. 2013;4(1):9.

115. Cruz E, Descalzi G, Steinmetz A, Scharfman HE, Katzman A, Alberini CM. CIM6P/IGF-2 Receptor Ligands Reverse Deficits in Angelman Syndrome Model Mice. Autism Res. 2020.

116. Glaze DG, Neul JL, Kaufmann WE, Berry-Kravis E, Condon S, Stoms G, et al. Double-blind, randomized, placebo-controlled study of trofinetide in pediatric Rett syndrome. Neurology. 2019;92(16):e1912-e25.

117. Berry-Kravis E, Horrigan JP, Tartaglia N, Hagerman R, Kolevzon A, Erickson CA, et al. A Double-Blind, Randomized, PlaceboControlled Clinical Study of Trofinetide in the Treatment of Fragile X Syndrome. Pediatr Neurol. 2020;110:30-41.

118. Mendola CE, Backer JM. Lovastatin blocks N-ras oncogene-induced neuronal differentiation. Cell Growth Differ. 1990;1(10):499-502.

119. Cerezo-Guisado MI, Garcia-Roman N, Garcia-Marin LJ, Alvarez-Barrientos A, Bragado MJ, Lorenzo MJ. Lovastatin inhibits the extracellular-signal-regulated kinase pathway in immortalized rat brain neuroblasts. Biochem J. 2007;401(1):175-83.

120. Santa-Catalina MO, Garcia-Marin LJ, Bragado MJ. Lovastatin effect in rat neuroblasts of the CNS: inhibition of cap-dependent translation. J Neurochem. 2008;106(3):1078-91.

121. Ottenhoff MJ, Krab LC, Elgersma Y. Considerations for Clinical Therapeutic Development of Statins for Neurodevelopmental Disorders. eNeuro. 2020;7(2).

122. Li W, Cui Y, Kushner SA, Brown RA, Jentsch JD, Frankland PW, et al. The HMG-CoA reductase inhibitor lovastatin reverses the learning and attention deficits in a mouse model of neurofibromatosis type 1. Curr Biol. 2005;15(21):1961-7.

123. Muscas M, Louros SR, Osterweil EK. Lovastatin, not Simvastatin, Corrects Core Phenotypes in the Fragile X Mouse Model. eNeuro. 2019;6(3). 
124. Chung L, Bey AL, Towers AJ, Cao X, Kim IH, Jiang YH. Lovastatin suppresses hyperexcitability and seizure in Angelman syndrome model. Neurobiol Dis. 2018;110:12-9.

125. Kumar V, Joshi T, Vatsa N, Singh BK, Jana NR. Simvastatin Restores HDAC1/2 Activity and Improves Behavioral Deficits in Angelman Syndrome Model Mouse. Front Mol Neurosci. 2019;12:289.

126. Payne JM, Barton B, Ullrich NJ, Cantor A, Hearps SJ, Cutter $\mathrm{G}$, et al. Randomized placebo-controlled study of lovastatin in children with neurofibromatosis type 1. Neurology. 2016;87(24):2575-84.

127. Thurman AJ, Potter LA, Kim K, Tassone F, Banasik A, Potter SN, et al. Controlled trial of lovastatin combined with an open-label treatment of a parent-implemented language intervention in youth with fragile X syndrome. J Neurodev Disord. 2020;12(1):12.

128. Garrido-Mesa N, Zarzuelo A, Galvez J. Minocycline: far beyond an antibiotic. Br J Pharmacol. 2013;169(2):337-52.

129. Dziembowska M, Pretto DI, Janusz A, Kaczmarek L, Leigh MJ, Gabriel N, et al. High MMP-9 activity levels in fragile X syndrome are lowered by minocycline. Am J Med Genet A. 2013;161A(8):1897-903.

130. Bilousova TV, Dansie L, Ngo M, Aye J, Charles JR, Ethell DW, et al. Minocycline promotes dendritic spine maturation and improves behavioural performance in the fragile $\mathrm{X}$ mouse model. J Med Genet. 2009;46(2):94-102.

131. Grieco JC, Ciarlone SL, Gieron-Korthals M, Schoenberg MR, Smith AG, Philpot RM, et al. An open-label pilot trial of minocycline in children as a treatment for Angelman syndrome. BMC Neurol. 2014; $14: 232$.

132. Ruiz-Antoran B, Sancho-Lopez A, Cazorla-Calleja R, LopezPajaro LF, Leiva A, Iglesias-Escalera G, et al. A randomized placebo controlled clinical trial to evaluate the efficacy and safety of minocycline in patients with Angelman syndrome (A-MANECE study). Orphanet J Rare Dis. 2018;13(1):144.

133. Sonzogni M, Wallaard I, Santos SS, Kingma J, du Mee D, van Woerden GM, et al. A behavioral test battery for mouse models of Angelman syndrome: a powerful tool for testing drugs and novel Ube3a mutants. Mol Autism. 2018;9:47.

134. Wang J, Lou SS, Wang T, Wu RJ, Li G, Zhao M, et al. UBE3Amediated PTPA ubiquitination and degradation regulate PP2A activity and dendritic spine morphology. Proc Natl Acad Sci U S A. 2019;116(25):12500-5.

135. Sun AX, Yuan Q, Fukuda M, Yu W, Yan H, Lim GGY, et al. Potassium channel dysfunction in human neuronal models of Angelman syndrome. Science. 2019;366(6472):1486-92.

136. Sun J, Liu Y, Zhu G, Cato C, Hao X, Qian L, et al. PKA and Ube3a regulate SK2 channel trafficking to promote synaptic plasticity in hippocampus: Implications for Angelman Syndrome. Sci Rep. 2020;10(1):9824.

137. Sheehan JJ, Benedetti BL, Barth AL. Anticonvulsant effects of the BK-channel antagonist paxilline. Epilepsia. 2009;50(4):711-20.

138. Cruvinel E, Budinetz T, Germain N, Chamberlain S, Lalande M, Martins-Taylor K. Reactivation of maternal SNORD116 cluster via SETDB1 knockdown in Prader-Willi syndrome iPSCs. Hum Mol Genet. 2014;23(17):4674-85.

139. Huang HS, Allen JA, Mabb AM, King IF, Miriyala J, TaylorBlake B, et al. Topoisomerase inhibitors unsilence the dormant allele of Ube3a in neurons. Nature. 2011;481(7380):185-9.

140. Garst J. Safety of topotecan in the treatment of recurrent smallcell lung cancer and ovarian cancer. Expert Opin Drug Saf. 2007;6(1):53-62.

141. Stein CA, Castanotto D. FDA-Approved Oligonucleotide Therapies in 2017. Mol Ther. 2017;25(5):1069-75.

142. Schmid RS, Deng X, Panikker P, Msackyi M, Breton C, Wilson JM. CRISPR/Cas9 directed to the Ube3a antisense transcript improves Angelman syndrome phenotype in mice. J Clin Invest. 2021.
143. Wolter JM, Mao H, Fragola G, Simon JM, Krantz JL, Bazick HO, et al. Cas9 gene therapy for Angelman syndrome traps Ube3aATS long non-coding RNA. Nature. 2020;587(7833):281-4.

144. Daily JL, Nash K, Jinwal U, Golde T, Rogers J, Peters MM, et al. Adeno-associated virus-mediated rescue of the cognitive defects in a mouse model for Angelman syndrome. PLoS One. 2011;6(12):e27221.

145. Born HA, Martinez LA, Levine AT, Harris SE, Mehra S, Lee WL, et al. Early Developmental EEG and Seizure Phenotypes in a Full Gene Deletion of Ubiquitin Protein Ligase E3A Rat Model of Angelman Syndrome. eNeuro. 2021;8(2).

146. den Bakker H, Sidorov MS, Fan Z, Lee DJ, Bird LM, Chu CJ, et al. Abnormal coherence and sleep composition in children with Angelman syndrome: a retrospective EEG study. Mol Autism. 2018;9:32.

147. Frohlich J, Bird LM, Dell'Italia J, Johnson MA, Hipp JF, Monti MM. Erratum: High-voltage, diffuse delta rhythms coincide with wakeful consciousness and complexity in Angelman syndrome. Neurosci Conscious. 2020;2020(1):niaa021.

148. Chirmule N, Propert K, Magosin S, Qian Y, Qian R, Wilson J. Immune responses to adenovirus and adeno-associated virus in humans. Gene Ther. 1999;6(9):1574-83.

149. Glessner JT, Wang K, Cai G, Korvatska O, Kim CE, Wood S, et al. Autism genome-wide copy number variation reveals ubiquitin and neuronal genes. Nature. 2009;459(7246):569-73.

150. Moreno-De-Luca D, Sanders SJ, Willsey AJ, Mulle JG, Lowe $\mathrm{JK}$, Geschwind DH, et al. Using large clinical data sets to infer pathogenicity for rare copy number variants in autism cohorts. Mol Psychiatry. 2013;18(10):1090-5.

151. Pinto D, Pagnamenta AT, Klei L, Anney R, Merico D, Regan R, et al. Functional impact of global rare copy number variation in autism spectrum disorders. Nature. 2010;466(7304):368-72.

152. Finucane BM, Lusk L, Arkilo D, Chamberlain S, Devinsky O, Dindot S, et al. 15q Duplication Syndrome and Related Disorders. In: Adam MP, Ardinger HH, Pagon RA, Wallace SE, Bean LJH, Stephens K, et al., editors. GeneReviews((R)). Seattle (WA) 1993.

153. Cook EH, Jr., Lindgren V, Leventhal BL, Courchesne R, Lincoln A, Shulman C, et al. Autism or atypical autism in maternally but not paternally derived proximal $15 \mathrm{q}$ duplication. Am J Hum Genet. 1997;60(4):928-34.

154. Urraca N, Hope K, Victor AK, Belgard TG, Memon R, Goorha $\mathrm{S}$, et al. Significant transcriptional changes in $15 \mathrm{q}$ duplication but not Angelman syndrome deletion stem cell-derived neurons. Mol Autism. 2018;9:6.

155. Hillman PR, Christian SGB, Doan R, Cohen ND, Konganti K, Douglas K, et al. Genomic imprinting does not reduce the dosage of UBE3A in neurons. Epigenetics Chromatin. 2017;10:27.

156. Silva-Santos S, van Woerden GM, Bruinsma CF, Mientjes E, Jolfaei MA, Distel B, et al. Ube3a reinstatement identifies distinct developmental windows in a murine Angelman syndrome model. J Clin Invest. 2015;125(5):2069-76.

157. Sonzogni M, Hakonen J, Bernabe Kleijn M, Silva-Santos S, Judson $\mathrm{MC}$, Philpot BD, et al. Delayed loss of UBE3A reduces the expression of Angelman syndrome-associated phenotypes. Mol Autism. 2019;10:23

158. Zylka MJ. Prenatal Treatment Path for Angelman Syndrome and Other Neurodevelopmental Disorders. Autism Res. 2019.

Publisher's Note Springer Nature remains neutral with regard to jurisdictional claims in published maps and institutional affiliations. 